\title{
Common diseases mimicking lumbar disc herniation and their treatment
}

\author{
Kyongsong Kim ${ }^{1}$, Toyohiko Isu², Daijiro Morimoto ${ }^{3}$, Naotaka Iwamoto ${ }^{4}$, Rinko Kokubo ${ }^{1}$, Juntaro Matsumoto ${ }^{2}$, Takao \\ Kitamura ${ }^{3}$, Atsushi Sugawara ${ }^{5}$, Akio Morita ${ }^{3}$
}

IDepartment of Neurosurgery, Chiba Hokuso Hospital, Nippon Medical School, Inzai-city, Chiba 270-1694, Japan.

${ }^{2}$ Department of Neurosurgery, Kushiro Rosai Hospital, Kushiro-city, Hokkaido 085-0088, Japan.

${ }^{3}$ Department of Neurosurgery, Nippon Medical School, Bunkyo-ku, Tokyo 113-8603, Japan.

${ }^{4}$ Department of Neurosurgery, Teikyo University, Itabashi-ku, Tokyo 173-8606, Japan.

${ }^{5}$ Department of Neurosurgery, Iwate Medical University, Morioka-city, Iwate 020-8505, Japan.

Correspondence to: Dr. Kyongsong Kim, Department of Neurosurgery, Chiba Hokuso Hospital, Nippon Medical School, 1715, Kamagari, Inzai-city, Chiba 270-1694, Japan. E-mail: kyongson@nms.ac.jp

How to cite this article: Kim K, Isu T, Morimoto D, Iwamoto N, Kokubo R, Matsumoto J, Kitamura T, Sugawara A, Morita A. Common diseases mimicking lumbar disc herniation and their treatment. Mini-invasive Surg 2017;1:43-51.

\begin{tabular}{l} 
Article history: \\
Received: $22-02-2017$ \\
Accepted: $14-03-2017$ \\
Published: $30-06-2017$ \\
\hline Key words: \\
Entrapment neuropathy, \\
peripheral nerve, \\
neurolysis, \\
diagnosis, \\
treatment, \\
paralumbar spine disease
\end{tabular}

\section{INTRODUCTION}

Lumbar disc herniation (LDH) is common; its symptoms of leg pain, numbness, and lowback pain (LBP), are also reported by patients with peripheral nerve and paralumbar spine diseases. Since they can cause intermittent claudication, thought to be specific to lumbar spine disease, differential diagnosis can be difficult. As misdiagnosis can result in failed back surgery syndrome (FBSS), spinal surgeons must be able to differentiate them from LDH.

\begin{abstract}
Lumbar disc herniation (LDH) is a common disease characterized by leg pain, numbness, and low back pain, which are also encountered in peripheral nerve and paralumbar spine disease. This study describes other diseases with symptoms similar to LDH. Patients with paralumbar spine diseases such as superior cluneal nerve entrapment neuropathy (NEN), gluteus medius muscle pain, piriformis syndrome, and sacroiliac joint pain experience lowback, buttock, and leg pain. Peripheral nerve diseases of the leg including lateral femoral cutaneous NEN, common and superficial peroneal NEN, and tarsal tunnel syndrome also cause leg symptoms. These diseases can produce intermittent claudication, thought to be specific to lumbar spine disease, and can be misdiagnosed as LDH. They are rather common and can be treated less invasively. As a misdiagnosis may result in failed back-surgery syndrome, it is important to differentiate between $\mathrm{LDH}$ and the diseases described here.
\end{abstract}

\section{PARA-LUMBAR SPINE DISEASES}

\section{Superior cluneal nerve entrapment neuropathy Definition and symptoms}

The superior cluneal nerve (SCN) is a sensory nerve that originates from the lower thoracic and lumbar posterior nerve. It is comprised of 4 to 6 nerves, runs around the paraspinal muscle, penetrates the thoracolumbar fascia near the iliac crest, and ends at the buttock [Figure 1]. The clinical features and etiology

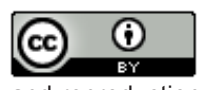

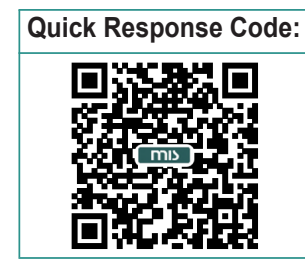




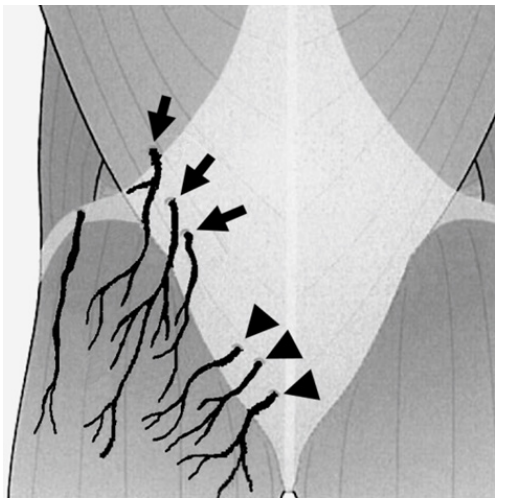

Figure 1: The superior cluneal nerve (arrows) consists of 4-6 nerves; it runs around the paraspinal muscle and penetrates the thoraco-lumbar fascia near the iliac crest before it arrives at the buttock. The middle cluneal nerve is identified by arrowheads

of SCN-entrapment neuropathy (EN) remain poorly understood. LBP occurs when the SCN is entrapped where it penetrates the thoraco-lumbar fascia. LBP attributable to SCN-EN involves the iliac crest and buttocks and can be misdiagnosed as a lumbar disorder. The reported incidence of SCN-EN ranges $1.6-14 \%$. $^{[1,2]}$

The most common symptom of SCN-EN is LBP around the iliac crest. It is exacerbated by lumbar movements involving flexion, extension, bending, rotation, standing, and walking. It can produce intermittent claudication, with $50 \%$ of patients reporting leg symptoms. ${ }^{[1,3]}$ As these symptoms are similar to those of lumbar disease, their differentiation is important for treatment planning.

The pathogenesis of SCN-EN remains unknown. It is seen in patients with vertebral compression fractures, LDH, lumbar spinal canal stenosis, FBSS, and Parkinson's disease..$^{[1,3-6]}$ As it is also encountered in the elderly, soldiers, and athletes, age-related spondylotic changes, sports-related activities, high body training, and trunk rotation may be related to the manifestation of SCN-EN. ${ }^{[1,5-8]}$

\section{Diagnosis and treatment}

The SCN is thin and difficult to identify through the skin surface. As SCN-EN cannot be identified with radiological and electrophysiological studies, its diagnosis is based on clinical symptoms. ${ }^{[2,9]}$ When we suspect SCN-EN because patients report LBP involving the iliac crest and buttocks, we identify the trigger point that elicits radiating pain over the posterior iliac crest located approximately $7 \mathrm{~cm}$ from the midline where the SCN penetrates the thoraco-lumbar fascia to confirm entrapment. The trigger point has been localized in earlier reports and is not affected by patient age, height, gender, or race. When SCN block successfully decreases pain, we make a diagnosis of SCN-EN.

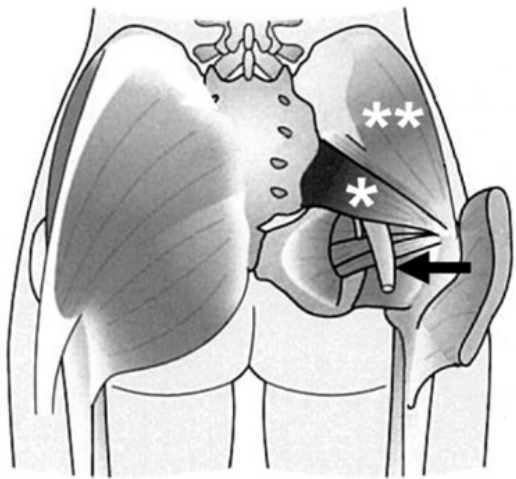

Figure 2: The location of the gluteus medius muscle (GMeM) (** and piriformis muscle $\left({ }^{\star}\right)$. The GMeM $\left({ }^{* *}\right)$ is located in the buttock over the gluteus minimus and partially under the gluteus maximus muscle; it is covered by a tight gluteal aponeurosis. The piriformis muscle $\left(^{*}\right)$ connects the sacrum and greater trochanter. Loading of this muscle results in buttock pain and affects the adjacent sciatic nerve (arrow)

SCN-EN can be treated by less invasive procedures such as local SCN block and SCN neurolysis under local anesthesia. We usually perform peripheral nerve surgery under local anesthesia without nerve block using no special techniques because we want to observe symptom changes and monitor the affected nerve during surgery. Approximately $28-100 \%$ of patients with SCN-EN respond to SCN-EN blocking. ${ }^{[1,2,7]}$ In some instances, SCN block is useful for treating refractory severe LBP. If only transient pain amelioration is achieved, SCN blockage can be repeated. When SCN-EN cannot be controlled by observation therapy including SCN blocks, it can be treated by less invasive SCN neurolysis under local anesthesia. ${ }^{[9-11]}$

\section{Gluteus medius muscle pain \\ Definition and symptoms}

The gluteus medius muscle (GMeM) is located in the buttock over the gluteus minimus and partially under the gluteus maximus muscle; it is covered by a tight gluteal aponeurosis [Figure 2]. The GMeM supports the pelvis and femur when standing on one leg, walking, and running. GMeM pain results in buttock pain. ${ }^{[6,12]}$ It is elicited by walking, prolonged sitting, standing, and standing on one leg. Lateral and posterior femoral pain is reported by $80 \%$ of patients. ${ }^{[12]}$ The symptoms are similar to those of lumbar disease, and differentiation of GMeM from LBP is important for treatment planning. Given its size, the GMeM generates an exceptionally large force, and this background may be related to GMeM pain severity. ${ }^{[13]}$ The GMeM plays a significant role in chronic LBP. ${ }^{[14-16]}$

\section{Diagnosis and treatment}

GMeM pain cannot be identified radiologically, so its diagnosis relies on clinical symptoms. ${ }^{[6,12]}$ In our 


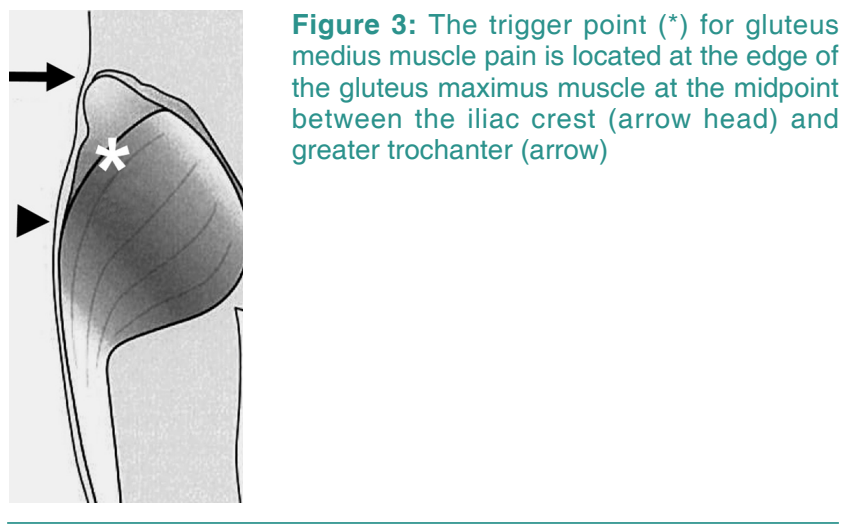

practice, we consider GMeM involvement in buttock pain when it is located around this muscle. The trigger point is located on the GMeM at the edge of the gluteus maximus muscle equidistant from the iliac crest and greater trochanter [Figure 3]. Some patients report pain radiation to the lateral-posterior thigh. When transient pain amelioration is obtained by local GMeM block, we diagnose GMeM pain.

When GMeM pain cannot be controlled by medication and physiotherapy, GMeM block may be useful. Some patients experience gait disturbance due to transient leg paralysis after blockage. Non-responders to conservative therapy may require less invasive GMeM decompression surgery under local anesthesia. ${ }^{[6,12]}$ This treatment can benefit even very old patients with intractable buttock and leg pain due to the GMeM. Peripheral block and less invasive surgery under local anesthesia are other treatment options. ${ }^{[6]}$

\section{Piriformis syndrome \\ Definition and symptoms}

The piriformis muscle connects the sacrum and greater trochanter. When it is overburdened, buttock pain also involving the adjacent sciatic nerve with nerve pain down to the lower thigh may be experienced. The pain is similar to that elicited by $\mathrm{S} 1$ radiculopathy and may be attributable to anatomic anomalies of the piriformis and sciatic nerve. It is more common in women than men. ${ }^{[17,18]}$

There are no specific symptoms. Patients report lower buttock pain and S1-like sciatic pain that rarely involves the ankle. The symptoms are exacerbated by prolonged sitting, stairclimbing, and walking. ${ }^{[19,20]}$ Some patients experience decreased pain with walking. The etiology of piriformis syndrome involves exercise load, trauma, and tumor; lumbar spine disease may be an idiopathic cause.

The accurate diagnosis of piriformis syndrome avoids FBSS and insufficient decompression after surgery.
Among patients with LBP, $5-17 \%$ manifest piriformis syndrome. ${ }^{[17,19,21-23]}$ Some patients develop piriformis syndrome after percutaneous endoscopic lumbar discectomy (PELD). Kim and $\mathrm{Kim}^{[22]}$ reported that the incidence of piriformis syndrome was $13.7 \%$. Within 3 months of PELD, $40.4 \%$ of operated patients presented with piriformis syndrome; its incidence was highest in the first postoperative month. Their observations suggest that heightened anxiety in patients undergoing PELD under local anesthesia may increase the incidence of piriformis syndrome elicited by walking. They suggested that general anesthesia may reduce the incidence of piriformis syndrome after PELD, although local anesthesia is preferable because it allows for intraoperative monitoring. Anxiolytic administration makes intraoperative patient cooperation difficult, particularly in older patients, and their use may have adverse effects. A proper preoperative period stretching of the piriformis muscle may be useful in locally anesthetized patients.

\section{Diagnosis and treatment}

Piriformis syndrome cannot be identified by radiological and electrophysiological studies; its diagnosis is based on clinical symptoms and palpation. ${ }^{[18-22]}$ During palpation, the swollen, stiff piriformis muscle is identified as a sausage-shaped mass over the piriformis muscle. There is tenderness, and some patients report radiating pain along the sciatic nerve. Symptom alleviation obtained by piriformis muscle block is diagnostic. ${ }^{[18,20-22]}$

Piriformis muscle stretching is useful in addition to medication and rehabilitation [Figure 4]. Some patients experience pain alleviation upon piriformis muscle stretching, but this exercise must be continued for more than 2 weeks. When these methods fail, piriformis muscle block may be useful. Piriformis muscle block may elicit transient leg paralysis 30-60 min after injection when the anesthetic reaches the sciatic nerve. Nonresponders may require piriformis muscle dissection.

\section{Sacroiliac joint pain}

\section{Definition and symptoms}

The sacroiliac joint (SIJ) connects the spine and pelvis; it is comprised of articular and posterior ligamentous compartments. It is reinforced with hard ligaments and moves only slightly. SIJ pain can be elicited by everyday activities and involves both articular and posterior ligament regions. It is felt not only in the lower back and buttocks but also in the groin and lower extremities, it can be difficult to discern from pain secondary to other disorders. The major pathological factor in SIJ pain is joint dysfunction. ${ }^{[24]}$ Repetitive movements and/or accidental minor subluxation of the SIJ may damage 


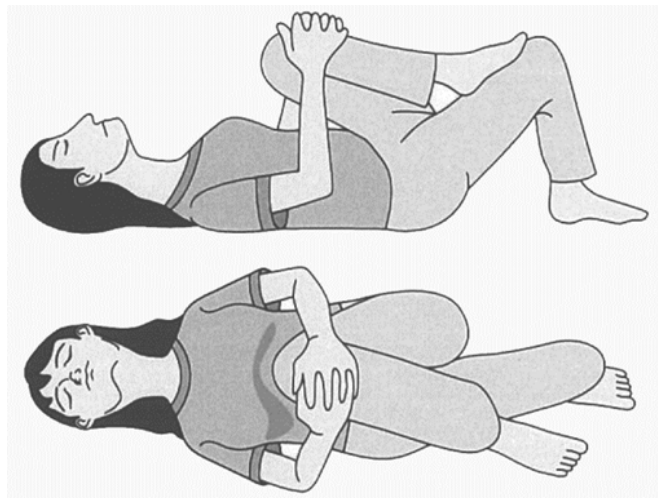

Figure 4: Piriformis muscle stretching

SIJ-related structures such as the joint capsule and the posterior ligament.

SIJ pain is commonly perceived in the gluteal region; it can be referred to the lower limbs and groin region, and is similar to symptoms due to lumbar diseases. ${ }^{[24-26]}$ The pain area tends to be located around or within $2 \mathrm{~cm}$ of the posterosuperior iliac spine (PSIS). SIJ pain should be considered in patients reporting lowerback and buttock pain. ${ }^{[24,27]}$ Approximately $50 \%$ of patients with SIJ pain experience groin pain, ${ }^{[24,28,29]}$ which is exacerbated by sitting on a backless chair. ${ }^{[24]}$

While SIJ pain may occur alone, $39 \%$ of patients also manifested LDH and LSS. ${ }^{[30]}$ It has been reported after lumbar fusion and lumbar decompression surgery. ${ }^{[31-33]}$ In patients with lumbogluteal and/or lower extremity pain and a high SIJ-related score, ${ }^{[24]}$ SIJ pain should be considered even in the absence of lumbar disease or prior lumbar surgery.

\section{Diagnosis and treatment}

As it is difficult to identify SIJ pain radiologically, its diagnosis is based on clinical symptoms and the effect of SIJ block. Kurosawa et al. ${ }^{[24]}$ proposed a score for diagnosing SIJ pain to distinguish it from pain elicited by other lumbar diseases [Table 1]. Their scoring system includes six items and is useful for both diagnosing and understanding SIJ pain. Patients often point to an area within $2 \mathrm{~cm}$ around the PSIS as the most painful area when instructed to identify the affected area with one finger (one-finger test). The SIJ shear test is the most useful provocation test. With the patient in the prone position, the examiner places a palm over the patient's posterior iliac wing and thrusts the palm inferiorly to produce a shearing force across the SIJ.

Besides medication and rehabilitation, conservative approaches include a pelvic belt and SIJ block. Blocking the posterior ligament and periarticular region of the SIJ under fluoroscopic guidance yielded more effective

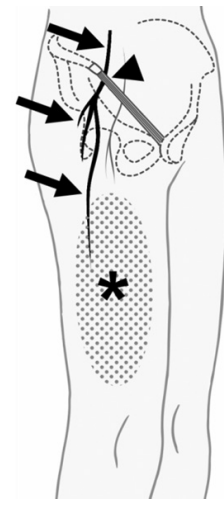

Figure 5: The course and entrapment point (arrowhead) of the lateral femoral cutaneous nerve (arrow). This sensory nerve branches off the L2 and L3 nerve roots, merges, passes through the inguinal ligament inside the superior iliac spine, and then distributes subcutaneously through the femoral fascia $\left.{ }^{*}\right)$. From Clinical diagnosis for low back pain by palpation (2015), Isu T \& Kim K, CHUGAIIGAKU. CO., LTD

pain relief than intra-articular SIJ injection. $[24,27,28,34]$ Injecting a local anesthetic into the posterior ligament can also relieve SIJ pain. While intra-articular SIJ injection is not recommended as a definitive diagnostic tool for pelvic girdle pain, it can be combined with the injection of a local anesthetic into the extra-articular SIJ ligaments to alleviate pain. ${ }^{[3,35]}$ SIJ denervation or fixation is a treatment option in non-responders.

\section{PERIPHERAL NERVE DISEASES}

\section{Lateral femoral cutaneous nerve EN}

\section{Definition and symptoms}

The lateral femoral cutaneous nerve (LFCN) is a sensory nerve that branches off the L2 and L3 nerve roots, merges, passes through the inguinal ligament inside the superior iliac spine, and is then distributed subcutaneously through the femoral fascia [Figure 5]. The incidence of LFCN-EN is 33-43 individuals per 100,000; the site where the nerve penetrates the inguinal ligament is often involved. ${ }^{[36,37]}$

Obesity, pregnancy, compression by tight undergarments and corsets, lower abdominal surgery, autogenous iliac bone, and nerve compression due to posterior spinal surgery in the prone position have been reported to be implicated; $77 \%$ of LFCN-EN is idiopathic. ${ }^{[36-38]}$ Diabetes and alcoholism are metabolic risk factors for LFCN-EN, which can be unilateral or bilateral. ${ }^{[38-40]}$ The symptoms are pain, abnormal perception, numbness, and a burning sensation in the

Table 1: Sacroiliac joint pain scoring ${ }^{[24]}$

\begin{tabular}{lcc}
\hline Item & Score & Odds ratio \\
\hline 1. One-finger test & 3 & 25.9 \\
2. Groin pain & 2 & 14.5 \\
3. Pain while sitting on achair & 1 & 1.4 \\
4. Sacroiliac joint shear test & 1 & 1.8 \\
5. PSIS tenderness & 1 & 2.2 \\
6. STL tenderness & 1 & 2.2 \\
Total score & 9 & \\
\hline
\end{tabular}

PSIS: posterosuperior iliac spine; STL: sacrotuberous ligament. Scores above 4 are considered high SIJ pain scores 


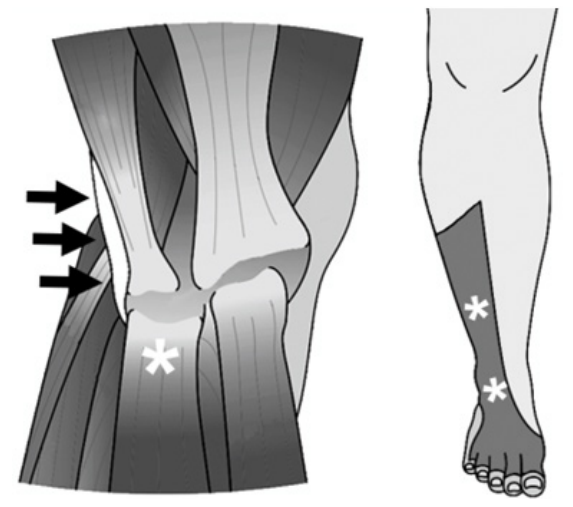

Figure 6: The common peroneal nerve (arrow) runs around the fibular head, then between the soleus and the peroneus longus muscle (PLM) $\left({ }^{*}\right)$, and then into the PLM. Patients experience pain and paresthesia of the affected area, the lateral aspect of the lower calf, and the dorsum of the foot $\left({ }^{* *}\right)$

anterior lateral region of the thigh; they are elicited by hip joint movement and alleviated by squatting. Some patients complain of intermittent claudication. ${ }^{[38,41,42]}$

\section{Diagnosis and treatment}

The symptoms above and Tinel-like signs at the nerve penetration site inside the superior iliac spine are diagnostically relevant. In some patients without clear Tinel-like symptoms, the disappearance of symptoms after nerve block is useful for a diagnosis. Electrophysiological studies can also be helpful. Patients with symptoms clearly attributable to LFCNEN may report perception anomalies on the outside of the thigh when the nerve is compressed in the pelvis or in the presence of a retroperitoneal tumor. Consequently, pelvic lesions must be ruled out when blocking fails to be effective.

Conservative therapy and nerve block are effective in $90 \%$ of patients. ${ }^{[42-44]}$ Tagliafico et al. ${ }^{[42]}$ reported that $80 \%$ of patients improved after a single block; others required 2 blocks to decrease symptoms. The nerve block is applied at the site with Tinel-like symptoms, $2 \mathrm{~cm}$ inside and $2 \mathrm{~cm}$ below the anterior superior iliac spine. As the anesthetic infiltrates the femoral nerve running on the inside, approximately $5 \%$ of patients experience transient femoral nerve paralysis. ${ }^{[43,45]}$ Non-responders to conservative therapy may require neurolysis or neurectomy under local anesthesia. ${ }^{[38,46,47]}$

\section{Common peroneal nerve EN}

\section{Definition and symptoms}

Common peroneal nerve (CPN)-EN is the most common peripheral entrapment neuropathy eliciting leg symptoms. The CPN runs around the fibular head and then between the soleus and peroneus longus muscle (PLM) to the inner PLM [Figure 6]; it can become entrapped in this area. As the nerve runs a shallow course on the bone, external compression neuropathy is not infrequent. However, EN has been reported in patients whose daily activities failed to account for its elicitation. ${ }^{[48-50]}$

The symptoms are pain and paresthesia of the affected area on the lateral aspect of the lower calf and the dorsum of the foot. Drop foot is a severe symptom, although some patients report only pain and paresthesia without severe paresis. ${ }^{[48-52]}$ Walking and prolonged standing may lead to symptom exacerbation and intermittent claudication.

\section{Diagnosis and treatment}

CPN-EN cannot be diagnosed radiologically. While nerve conduction studies may be useful, the anomaly may not be detectable in patients with dynamic neuropathy-like intermittent claudication. ${ }^{[48-51,53]}$ In these situations, it can be difficult to distinguish CPN-EN from lumbar spine disease because the symptomatic area is similar to L5 radiculopathy with intermittent claudication. ${ }^{[48-50]}$ CPN-EN diagnosis is based on clinical symptoms. Although the Tinel-like sign is useful diagnostic information, it may be absent. ${ }^{[51]}$

Repetitive plantar flexion of the ankle joint is a useful provocation test because the CPN is entrapped by the PLM and soleus muscle; ${ }^{[48,49]}$ these muscles are most heavily loaded during maximum plantar flexion. CPN-EN results in intermittent claudication. At a cutoff of $110 \mathrm{~s}$, sensitivity and specificity were $94.1 \%$, suggesting that the repetitive plantar flexion test is diagnostically useful. ${ }^{[48]}$

When conservative treatment fails, surgical neurolysis around the fibular head under local anesthesia is a useful treatment. It is important to intraoperatively confirm sufficient decompression by ankle movement because dynamic neuropathy is an important factor in CP-NEN etiology.

\section{Superficial peroneal nerve EN \\ Definition and symptoms}

CPN-EN is more common than superficial peroneal nerve (SPN)-EN. The SPN bifurcates from the CPN around the fibular head and runs along the peroneal tunnel between the peroneus longus/brevis muscles and the extensor digitorum longus muscle. The SPN can be entrapped in this area.

Patients with SPN entrapment report pain and paresthesia in the affected area, the lateral aspect of the lower calf, and the dorsum of the foot. Styf and Morbergfound SPN entrapment in 17 of 480 (3.5\%) patients with chronic leg pain. ${ }^{[54]}$ According to 


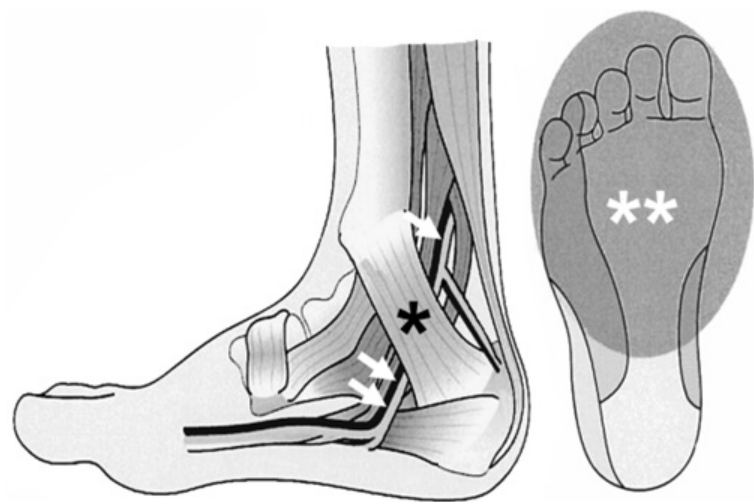

Figure 7: Tarsal tunnel syndrome is an entrapment neuropathy of the posterior tibial nerve (arrow) in the tarsal tunnel $\left({ }^{*}\right)$. Only the sole of the foot has symptoms $\left({ }^{* *}\right)$; there is no heel pain

others, ${ }^{[55-57]}$ SPN-EN was attributable to entrapment due to muscle herniation, trauma, compression by a mass lesion, (e.g. varicose veins or lipoma), or an idiopathic origin.

\section{Diagnosis and treatment}

SPN-EN diagnosis is based on its symptomatology because it is difficult to diagnose on radiological and nerve conduction studies. ${ }^{[54-57]}$ Its symptoms tend to be exacerbated by walking and exercise, and SPN-EN must be differentiated from other lumbar diseases. The Tinel-like sign is diagnostically useful. ${ }^{[54-57]}$ Tinel-like signs are occasionally observed at multiple compressed points along the SPN. ${ }^{[54]}$ SPN block with lidocaine may provide transient pain relief. SPN-EN can co-exist with CPN-EN; Franco et al. ${ }^{[56]}$ reported that $78 \%$ of patients who underwent SPN-EN surgery had undergone CPN decompression surgery. In patients with muscle herniation, static palpitation and radiological studies may not identify the lesion, and the loaded posture may be necessary for a correct diagnosis.

The decision to intervene surgically depends on SPNEN etiology. Neurolysis may be effective in patients with idiopathic origins. The area requiring decompression is not necessarily limited to the part with the Tinel sign. Some patients may require decompression involving the area from the PLM to the SPN exit point along the SPN.

\section{Tarsal tunnel syndrome: posterior tibial nerve EN}

\section{Definition and symptoms}

The tarsal tunnel is a fibro-osseous tunnel under the flexor retinaculum below the medial malleolus. The posterior tibial nerve bifurcates to the medial and lateral plantar nerve and passes inside the tarsal tunnel together with the posterior tibial artery and vein. Tarsal tunnel syndrome (TTS) is an entrapment neuropathy of the posterior tibial nerve within the tarsal tunnel [Figure 7].
The etiology of TTS has been ascribed to tumors; changes in anatomical structures due to trauma; and idiopathic factors such as tortuous vessels, hypertrophy of the flexor retinaculum, and fibrosis with a variety of origins. Compression of tortuous arteries and veins can elicit TTS, although a tortuous vein may be a normal variation. TTS was idiopathic in $18-69 \%$ of patients. ${ }^{[58-60]}$

The symptoms are sensory disturbance in the sole of the affected foot, paresthesia, a foreign-body sensation like walking on gravel, cold sensation, and burning or tingling. They are exacerbated by prolonged standing or walking; they do not involve the heel of the affected foot (heel sparing) because the branch to the heel bifurcates proximal to the tarsal tunnel. Heel sparing is therefore useful for the diagnosis of TTS. ${ }^{[58,59,61-63]}$

\section{Diagnosis and treatment}

An accurate diagnosis is difficult, and TSS is regularly underdiagnosed based on clinical symptoms affecting the plantar aspect of the foot. ${ }^{[61-64]}$ Although sonography, computed tomography, and magnetic resonance imaging studies are diagnostically useful in patients with space-occupying lesions, the identification of idiopathic TTS remains difficult. Falsepositive and false-negative findings make diagnosis of TTS based on electrophysiological means alone difficult. ${ }^{[61,65-67]} \mathrm{A}$ positive Tinel-like sign and radiating pain on the entrapment point of the tibial nerve in the tarsal tunnel are diagnostically useful. A positive Tinel sign is the best indicator of a favorable outcome after decompression surgery. ${ }^{[58,59,62,64]}$

TTS symptoms may be misdiagnosed as part of the symptomatology of spinal disease and as sequelae after spinal surgery. TTS was found in $4.8 \%$ of patients with lumbosacral radiculopathy and tends to complicate lumbar spine disease. FBSS should be considered in the absence of clear evidence of TTS. ${ }^{[68,69]}$ TTS must be ruled out or addressed when patients treated by spinal surgery continue to experience anterior sole numbness and/or pain.

When TTS fails to respond to observation therapy, we perform neurolysis under local anesthesia. ${ }^{[62,63]} \mathrm{We}$ make a 3-4-cm bow-like incision $1.5 \mathrm{~cm}$ below the medial malleolus over the point of the Tinel-like sign without using a tourniquet. In some cases, besides cutting the flexor retinaculum and opening the tarsal tunnel, sufficient decompression from the neurovascular band and transposition may be necessary. Although the outcome of surgery for idiopathic TTS tends to be good, some patients experience only partial or no improvement. ${ }^{[60,61,64,67]}$ Significant pain alleviation after tarsal tunnel decompression surgery has been 
reported by $44-90 \%$ of patients. An incorrect diagnosis, incomplete surgical decompression, adhesive neuritis, neural trauma or damage, systemic disease, double crush syndrome, and prolonged symptoms are factors that must be considered in patients with failed TTS surgery. ${ }^{[60,62,64,67]}$

\section{CONCLUSION}

We described typical peripheral nerve and paralumbar spine diseases with symptoms similar to those of $\mathrm{LDH}$. These diseases are common, and unless they are diagnosed and treated correctly, patients may progress to FBSS. In some instances, these diseases respond well to less invasive treatment methods, and some patients experience dramatic improvement. The surgical procedures described herein are less invasive and do not require sophisticated techniques.

It is important to recognize that the diseases we discussed may be associated with LDH. Therefore, a better understanding of specific diseases other than $\mathrm{LDH}$ and their treatment is necessary. Symptoms in patients with LDH may be attributable to such diseases, and they may accompany symptoms elicited by LDH. The careful analysis of factors that contribute to the patients' symptoms is important for making a correct diagnosis and may broaden the range of beneficial treatments and improve their quality of life.

\section{Authors' contributions}

Concept and design: K. Kim, T. Isu

Manuscript preparation: K. Kim

Manuscript editing: K. Kim, T. Isu

Literature search: D. Morimoto, N. Iwamoto, R. Kokubo,

J. Matsumoto, T. Kitamura

Manuscript review: A. Sugawara, A. Morita

\section{Financial support and sponsorship}

None.

\section{Conflicts of interest}

There are no conflicts of interest and no financial disclosures.

\section{Patient consent}

Not applicable.

\section{Ethics approval}

This review article is waived for ethical approval.

\section{REFERENCES}

1. Kuniya H, Aota Y, Kawai T, Kaneko K, Konno T, Saito T. Prospective study of superior cluneal nerve disorder as a potential cause of low back pain and leg symptoms. J Orthop Surg Res 2014;31:139.

2. Maigne JY, Doursounian L. Entrapment neuropathy of the medial superior cluneal nerve. Nineteen cases surgically treated, with a minimum of 2 years' follow-up. Spine 1997;22:1156-9.

3. Chiba Y, Isu T, Kim K, Iwamoto N, Morimoto D, Yamazaki K, Hokari M, Isobe M, Kusano M. Association between intermittent low-back pain and superior cluneal nerve entrapment neuropathy. $J$ Neurosurg Spine 2015;13:1-5.

4. Iwamoto N, Isu T, Kim K, Chiba Y, Kokubo R, Morimoto D, Shirai $\mathrm{S}$, Yamazaki K, Isobe M. Low back pain caused by superior cluneal nerve entrapment neuropathy in patients with Parkinson disease. World Neurosurg 2016;87:250-4.

5. Kim K, Isu T, Chiba Y, Iwamoto N, Yamazaki K, Morimoto D, Isobe $\mathrm{M}$, Inoue $\mathrm{K}$. Treatment of low back pain in patients with vertebral compression fractures and superior cluneal nerve entrapment neuropathies. Surg Neurol Int 2015;25:S619-21.

6. Kokubo R, Kim K, Isu T, Morimoto D, Iwamoto N, Kobayashi S, Morita A. Superior cluneal nerve entrapment neuropathy and gluteus medius muscle pain: their effect on very old patients with low back pain. World Neurosurg 2017;98:132-9.

7. Ermis MN, Yildirim D, Durakbasa MO, Tamam C, Ermis OE. Medial superior cluneal nerve entrapment neuropathy in military personnel; diagnosis and etiologic factors. J Back Musculoskelet Rehabil 2011;24:137-44

8. Speed S, Sims K, Weinrauch P. Entrapment of the medial branch of the superior cluneal nerve. A previously unrecognized cause of lower back pain in cricket fast bowlers. J Med Cases 2011;2:101-3.

9. Morimoto D, Isu T, Kim K, Imai T, Yamazaki K, Matsumoto R, Isobe M. Surgical treatment of superior cluneal nerve entrapment neuropathy: technical note. J Neurosurg Spine 2013;19:71-5.

10. Kim K, Isu T, Chiba Y, Morimoto D, Ohtsubo S, Kusano M, Kobayashi $\mathrm{S}$, Morita A. The usefulness of ICG video angiography in the surgical treatment of superior cluneal nerve entrapment neuropathy: technical note. J Neurosurg Spine 2013;19:624-8.

11. Daijiro M, Toyohiko I, Kyongsong K, Yasuhiro C, Naotaka I, Masanori I, Akio M. Long-term outcome of surgical treatment for superior cluneal nerve entrapment neuropathy. Spine 2016; DOI: 10.1097/BRS.0000000000001913.

12. Kim K, Isu T, Chiba Y, Iwamoto N, Morimoto D, Isobe M. Decompression of the gluteus medius muscle as a new treatment for buttock pain: technical note. Eur Spine J 2016;25:1282-8.

13. Ward SR, Winters TM, Blemker SS. The architectural design of the gluteal muscle group: implications for movement and rehabilitation. $J$ Orthop Sports Phys Ther 2010;40:95-102.

14. de Vet HC, Heymans MW, Dunn KM, Pop DP, van der Beek AJ, Macfarlane GJ, Bouter LM, Croft PR. Episodes of low back pain: a proposal for uniform definitions to be used in research. Spine 2002;27:2409-16

15. Dionne CE, Dunn KM, Croft PR, Nachemson AL, Buchbinder R, Walker BF, Wyatt M, Cassidy JD, Rossignol M, Leboeuf-Yde C, Hartvigsen J, Leino-Arjas P, Latza U, Reis S, Gil Del Real MT, Kovacs FM, Oberg B, Cedraschi C, Bouter LM, Koes BW, Picavet HS, van Tulder MW, Burton K, Foster NE, Macfarlane GJ, Thomas E, Underwood M, Waddell G, Shekelle P, Volinn E, Von Korff M. A consensus approach toward the standardization of back pain definitions for use in prevalence studies. Spine 2008;33:95-103.

16. Cooper NA, Scavo KM, Strickland KJ, Tipayamongkol N, Nicholson JD, Bewyer DC, Sluka KA. Prevalence of gluteus medius weakness in people with chronic low back pain compared to healthy controls. Eur Spine J 2016;25:1258-65.

17. Pace JB, Nagle D. Piriform syndrome. West J Med 1976;124:435-9.

18. Michel F, Decavel P, Toussirot E, Tatu L, Aleton E, Monnier G, Garbuio P, Parratte B. Piriformis muscle syndrome: diagnostic criteria and treatment of a monocentric series of 250 patients. Ann Phys 
Rehabil Med 2013;56:371-83.

19. Papadopoulos EC, Khan SN. Piriformis syndrome and low back pain: a new classification and review of the literature. Orthop Clin North Am 2004;35:65-71.

20. Miller TA, White KP, Ross DC. The diagnosis and management of piriformis syndrome: myths and facts. Can J Neurol Sci 2012;39:57783.

21. Kean Chen C, Nizar AJ. Prevalence of piriformis syndrome in chronic low back pain patients. A clinical diagnosis with modified FAIR test. Pain Pract 2013;13:276-81.

22. Kim JE, Kim KH. Piriformis syndrome after percutaneous endoscopic lumbar discectomy via the posterolateral approach. Eur Spine $J$ 2011;20:1663-8.

23. Robinson DR. Piriformis syndrome in relation to sciatic pain. Am J Surg 1947;73:355-8.

24. Kurosawa D, Murakami E, Ozawa H, Koga H, Isu T, Chiba Y, Abe E, Unoki E, Musha Y, Ito K, Katoh S, Yamaguchi T. A diagnostic scoring system for sacroiliac joint pain originating from the posterior ligament. Pain Med 2017;18:228-38.

25. Hancock MJ, Maher CG, Latimer J, Spindler MF, McAuley JH, Laslett M, Bogduk N. Systematic review of tests to identify the disc, SIJ or facet joint as the source of low back pain. Eur Spine J 2007;16:1539-50.

26. Vanelderen P, Szadek K, Cohen SP, De Witte J, Lataster A, Patijn J, Mekhail N, van Kleef M, Van Zundert J. Sacroiliac joint pain. Pain Pract 2010;10:470-8.

27. Murakami E, Aizawa T, Noguchi K, Kanno H, Okuno H, Uozumi H. Diagram specific to sacroiliac joint pain site indicated by one-finger test. J Orthop Sci 2008;13:492-7.

28. Kurosawa D, Murakami E, Aizawa T. Referred pain location depends on the affected section of the sacroiliac joint. Eur Spine J2015;24:5217.

29. Morimoto D, Isu T, Kim K, Matsumoto R, Isobe M. Unexplained lower abdominal pain associated with sacroiliac joint dysfunction. $J$ Nihon Med Sch 2011;78:257-60.

30. Bernard TN, Kirkaldy-Wills WH. Recognizing specific characteristics of nonspecific low back pain. Clin Orthop Relate Res 1985;217:26680 .

31. Liliang PC, Lu K, Liang CL, Tsai YD, Wang KW, Chen HJ. Sacroiliac joint pain after lumbar and lumbosacral fusion: findings using dual sacroiliac joint blocks. Pain Med 2011;12:565-70.

32. Maigne JY, Planchon CA. Sacroiliac joint pain after lumbar fusion. A study with anesthetic blocks. Eur Spine J 2005;14:654-8.

33. Schomacher M, Kunhardt O, Koeppen D, Moskopp D, Kienapfel H, Kroppenstedt S, Cabraja M. Transient sacroiliac joint-related pain is a common problem following lumbar decompressive surgery without instrumentation. Clin Neurol Neurosurg 2015;139:81-5.

34. Murakami E, Tanaka Y, Aizawa T, Ishizuka M, Kokubun S. Effect of periarticular and intraarticular lidocaine injections for sacroiliac joint pain: prospective comparative study. J Orthop Sci 2007;12:274-80.

35. Vleeming A, Albert HB, Ostgaard HC, Strusson B, Stuge B. European guidelines for the diagnosis and treatment of pelvic girdle pain. Eur Spine J 2008;17:794-819.

36. Parisi TJ, Mandrekar J, Dyck PJ, Klein CJ. Meralgia paresthetica: relation to obesity, advanced age, and diabetes mellitus. Neurology 2011;77:1538-42.

37. van Slobbe AM, Bohnen AM, Bernsen RM, Koes BW, BiermaZeinstra SM. Incidence rates and determinants in meralgia paresthetica in general practice. $J$ Neurol 2004;251:294-7.

38. Cheatham SW, Kolber MJ, Salamh PA. Meralgia paresthetica: a review of the literature. Int J Sports Phys Ther 2013;8:883-93.

39. Berini SE, Spinner RJ, Jentoft ME, Engelstad JK, Staff NP,
Suanprasert N, Dyck PJ, Klein CJ. Chronic meralgia paresthetica and neurectomy: a clinical pathologic study. Neurology 2014;82:1551-5.

40. Seror P, Seror R. Meralgia paresthetica: clinical and electrophysiological diagnosis in 120 cases. Muscle Nerve 2006;33:650-4.

41. Grossman MG, Ducey SA, Nadler SS, Levy AS. Meralgia paresthetica: diagnosis and treatment. J Am Acad Orthop Surg 2001;9:336-44.

42. Tagliafico A, Serafini G, Lacelli F, Perrone N, Valsania V, Martinoli C. Ultrasound-guided treatment of meralgia paresthetica (lateral femoral cutaneous neuropathy): technical description and results of treatment in 20 consecutive patients. J Ultrasound Med 2011;30:1341-6.

43. Haim A, Pritsch T, Ben-Galim P, Dekel S. Meralgia paresthetica: a retrospective analysis of 79 patients evaluated and treated according to a standard algorithm. Acta Orthop 2006;77:482-6.

44. Williams PH, Trzil KP. Management of meralgia paresthetica. $J$ Neurosurg 1991;74:76-80.

45. Konder H, Moysich F, Mattusch W. An accidental motor blockade of the femoral nerve following a blockade of the lateral femoral cutaneous nerve. Reg Anaesth 1990;13:122-3.

46. de Ruiter GC, Kloet A. Comparison of effectiveness of different surgical treatments for meralgia paresthetica: results of a prospective observational study and protocol for a randomized controlled trial. Clin Neurol Neurosurg 2015;134:7-11.

47. Emamhadi M. Surgery for meralgia paresthetica: neurolysis versus nerve resection. Turk Neurosurg 2012;22:758-62.

48. Iwamoto $\mathrm{N}$, Kim $\mathrm{K}$, Isu $\mathrm{T}$, Chiba $\mathrm{Y}$, Morimoto D, Isobe M. Repetitive plantar flexion test as an adjunct tool for the diagnosis of common peroneal nerve entrapment neuropathy. World Neurosurg 2016;86:484-9.

49. Kim K, Isu T, Kokubo R, Morimoto D, Kobayashi S, Morita A. Repetitive plantar flexion (provocation) test for the diagnosis of intermittent claudication due to peroneal nerve entrapment neuropathy: case report. NMC Case Rep J 2015;2:140-2.

50. Morimoto D, Isu T, Kim K, Sugawara A, Yamazaki K, Chiba Y, Iwamoto N, Isobe M, Morita A. Microsurgical decompression for peroneal nerve entrapment neuropathy. Neurol Med Chir 2015;55:66973.

51. Fabre T, Piton C, Andre D, Lasseur E, Durandeau A. Peroneal nerve entrapment. J Bone Joint Surg Am 1998;80:47-53.

52. Maalla R, Youssef M, Ben Lassoued N, Sebai MA, Essadam H. Peroneal nerve entrapment at the fibular head: outcomes of neurolysis. Orthop Traumatol Surg Res 2013;99:719-22.

53. Kitamura T, Morimoto D, Kim K, Morita A. Peroneal nerve entrapment neuropathy induced by playing the drum. Acta Neurochir 2016;158:967-8

54. Styf J, Morberg P. The superficial peroneal tunnel syndrome. Result of treatment by decompression. J Bone Joint Surg Br 1997;79:801-3.

55. Banerjee T, Koons DD. Superficial peroneal nerve entrapment. Report of two cases. J Neurosurg 1981;55:991-2.

56. Franco MJ, Phillips BZ, Lalchandani GR, Mackinnon SE Decompression of the superficial peroneal nerve: clinical outcomes and anatomical study. J Neurosurg 2017;126:330-5.

57. Styf J. Entrapment of the superficial peroneal nerve. Diagnosis and treatment of decompression. J Bone Joint Surg Br 1989;71:131-5.

58. Takakura Y, Kitada C, Sugimoto K, Tanaka Y, Tamai S. Tarsal tunnel syndrome. Causes and results of operative treatment. J Bone Joint Surg 1991;73:125-8.

59. Radin EL. Tarsal tunnel syndrome. Clin Orthop Relat Res 1983;181:167-70

60. Lam SJ. Tarsal tunnel syndrome. J Bone Joint Surg 1967;49:87-92.

61. Ahmad M, Tsang K, Mackenney PJ, Adedapo AO. Tarsal tunnel syndrome: a literature review. Foot Ankle Surg 2012;18:149-52. 
62. Kim K, Isu T, Morimoto D, Sasamori T, Sugawara A, Chiba Y, Isobe M, Kobayashi S, Morita A. Neurovascular bundle decompression without excessive dissection for tarsal tunnel syndrome. Neurol Med Chir 2014;54:901-6.

63. Kokubo R, Kim K, Isu T, Morimoto D, Iwamoto N, Kobayashi S, Morita A. The impact of tarsal tunnel syndrome on cold sensation in the pedal extremities. World Neurosurg 2016;92:249-54.

64. McSweeney SC, Cicheo M, Tarsal tunnel syndrome - a narrative literature review. Foot 2015;25:244-50.

65. Galardi G, Amadio S, Maderna L, Meraviglia MV, Brunati L, Dal Conte G, Comi G. Electrophysiologic studies in tarsal tunnel syndrome. Diagnostic reliability of motor distal latency, mixed nerve and sensory nerve conduction studies. Am J Phys Med Rehabil
1994;73:193-8.

66. Gould N, Alvarez R. Bilateral tarsal tunnel syndrome caused by varicosities. Foot Ankle 1983;3:290-2.

67. Pfeiffer WH, Cracchiolo A 3rd. Clinical results after tarsal tunnel decompression. J Bone Joint Surg Am 1994;76:1222-30.

68. Zheng C, Zhu Y, Jiang J, Ma X, Lu F, Jin X, Weber R. The prevalence of tarsal tunnel syndrome in patients with lumbosacral radiculopathy. Eur Spine J 2016;25:895-905.

69. Morimoto D, Isu T, Shimoda Y, Hamauchi S, Sasamori T, Sugawara A, Kim K, Matsumoto R, Isobe M. Assessing the treatment for sacroiliac joint dysfunction, piriformis syndrome and tarsal tunnel syndrome associated with lumbar degenerative disease. No Shinkei Geka 2009;37:873-9. 